\title{
ANTIFUNGAL ACTIVITY OF ACTINOBACTERIA WITH A POTENTIAL TO INHIBIT RICE BLAST FUNGUS MAGNAPORTHE ORYZAE (ANAMORPH PYRICULARIA ORYZAE)
}

\author{
THILAGAM R, BALAGURUNATHAN R, SANGEETHA M, HEMALATHA N*
}

Department of Microbiology, Periyar University, Salem, Tamil Nadu, India. Email: aarthihema2004@yahoo.com

Received: 13 December 2020, Revised and Accepted: 15 January 2021

ABSTRACT

Objective: The aims of the present study were to screen the actinobacteria with high potential ability to produce secondary metabolites that have inhibitory activity against plant pathogenic fungi, Magnaporthe oryzae. Production of secondary metabolites was analysis by thin-layer chromatography and bioautography assay.

Methods: Screening and selection of potential Streptomyces sp. morphological, cultural, physiological, and biochemical characterization of the screened isolate was carried out. Antifungal compound was confirmed by bioautography assay.

Results: Bioautography method use in this study was found to be antifungal fraction from the crude extract. Antifungal secondary metabolites can be readily located on the plates by observing clear zones where active compounds inhibit fungal growth.

Conclusion: The bioautography assay shows that this isolates can produce antifungal compound. Therefore, this isolate proves to be a promising microbe which can be further studied for its applications a biocontrol agent against rice blast fungi.

Keywords: Secondary metabolites, Streptomyces violaceoruber, Rice blast disease, Magnaporthe oryzae, Bioautography.

(C) 2021 The Authors. Published by Innovare Academic Sciences Pvt Ltd. This is an open access article under the CC BY license (http://creativecommons.org/ licenses/by/4.0/) DOI: http://dx.doi.org/10.22159/ajpcr.2021v14i3.40491. Journal homepage: https://innovareacademics.in/journals/index.php/ajpcr

\section{INTRODUCTION}

Rice is a staple food source for more than four billion people worldwide. However, rice is vulnerable to diseases, the most destructive among them being rice blast disease, which is caused by the fungus Magnaporthe oryzae (anamorph Pyricularia oryzae). The plant is prove to the disease at all stages of development, causing annual losses of approximately 30$45 \%$ in various rice producing regions. Synthetic fungicides are able to effectively control plant diseases, but some fungicides result in serious environmental and health issues primarily to farmers and consumers. Several studies have been performed for testing of the various compounds produced by Streptomyces on M. oryzae. The antibiotic Oligomycin A was first isolated from Streptomyces diastatochromogenes and was controlling several other plant pathogenic fungi such as Botrytis cinerea, Cladosporium cucumerinum, Colletotrichum lagenarium, Phytophthora capsici, Alternaria alternata, and Aspergillus niger in addition to M. oryzae [1-3]. Other compounds such as Pyrroles (Pyrrolo[1,2-a] pyrazine-1,4-dione, hexahydro-) are commonly found in various actinobacterial species [4,5]. Furthermore, Pyrrolo[1,2-a] pyrazine-1,4dione,hexahydro-3-(phenylmethyl) was found to be able to protect plants from disease causing plant pathogenic fungi and bacteria [6].

Due to the side effects of chemical pesticides, sustainable crop production through eco-friendly, clean, and green management is an essential requirement in the present alarming situation [7]. Therefore, there is growing interest in discovering and developing new, improved fungicides and pesticides based on natural products as well as introducing alternative measures such as biocontrol agents to manage plant diseases and farmers, consumers health.

Actinomycetes are abundant and widely distributed in soil, constituting to about $10-50 \%$ of the soil microflora community. Tyc et al. [8], Adegboye and Babalola [9], and other researchers have reported them to be important producers of secondary metabolites. The metabolites produced are varied in their biological activities and functions such as antifungal, insecticidal, antibacterial, and anthelmintic activities.
Actinomycetes, like other plant growth-promoting microbes, also produce phytohormone [10] and solubilize phosphate [11,12]. Streptomyces could indirectly act through increased plant fitness, induction of systemic resistance of plants, and production of bioactive compounds such as antibiotic compounds, siderophore, and some lytic enzymes such as glucanase [13]. Phenazines are a group of nitrogen-containing heterocyclic compounds derived from bacteria of diverse genera such as Pseudomonas, Streptomyces, Vibrio, and Pelagiobacter [14] and their derivatives phenazine-1-carboxamide and phenazine-1-carboxylic acid are considered as important compounds that showed remarkable antifungal activity against disease causing fungal plant pathogen [15].

The bioautography is one of the techniques useful in detecting bioactive compounds from bacterial extracts separated on thinlayer chromatogram. Hence, the objective of this study was to screen secondary metabolites that have inhibitory activity against rice blast plant pathogenic fungi confirmed by bioautography technique.

\section{METHODS}

Collection of fungal pathogen and actinobacterial strains Fungal pathogen collection

M. oryzae-6923 (anamorph P. oryzae) was collected from Indian Type Culture Collection.

\section{Actinobacterial strain collection}

Actinobacterial cultures were obtained from Actinobacterial Research Laboratory, Department of Microbiology, Periyar University. They included $\mathrm{N}_{126}, \mathrm{M}_{2}, \mathrm{M}_{32}, \mathrm{MS}_{1-10}, \mathrm{DS}_{7-9}, \mathrm{BS}_{26}, \mathrm{HS}_{3}, \mathrm{BS}_{18}$, and CSABNC1.

Screening of potential Streptomyces strain for bioactive compound production against $P$, oryzae

Primary screening

The 20 actinobacterial cultures were screened for their ability to control the fungal growth. An in vitro primary screening method was 
used to test the ability of actinobacterial isolates to inhibit the growth of $P$. oryzae. It was done with slight modification of agar plug method of Bharti et al. [16]. Mycelial disks of $6 \mathrm{~mm}$ diameter cut out using sterilized cork borer of 5-day-old actively growing pure actinobacterial colony were aseptically inoculated onto the center of potato dextrose agar (PDA) plates [17]. Similarly, P. oryzae mycelial disks of $6 \mathrm{~mm}$ diameter were cut out from the actively growing pure colony and placed on either side of actinobacteria $3 \mathrm{~cm}$ away from central inoculum. All plates were maintained in duplicates and incubated at $28^{\circ} \mathrm{C}$ for 7 days $[18,19]$

Inhibition of mycelia growth (\%): \% Inhibition of mycelia growth = $A-B / A \times 100$, where $A$ is the mycelial growth of pathogen in absence of antagonists; B the mycelial growth of pathogen in presence of antagonists [20]. The isolates exhibiting maximum zone of inhibition against the tested pathogens were selected for secondary screening.

\section{Secondary screening}

Actinobacterial isolates selected by primary screening were subjected to secondary screening by agar well diffusion method to test their antagonism upon fungal spore germination and growth. In secondary screening test, the actinobacterial isolates were inoculated in ISP2 medium, $\mathrm{pH} 7.0$, temperature $28^{\circ} \mathrm{C}$, and incubated for 7 days. After the incubation period, antifungal activity of crude sample was tested. The spore density was set by spectrophotometer adjusted to $80-85 \%$ transmittance at $530 \mathrm{~nm}$ with appropriate dilutions to get fungal spore counts of $10^{6}$ spores per $\mathrm{ml}$ [21]. The potential isolate screened was mass cultivated in ISP2 medium. This pure culture was further characterized for its identification.

Morphological, cultural, physiological, and biochemical characteristics of strain BS-26

The morphological, cultural, physiological, and biochemical characterization of the isolate was carried out as described in the international Streptomyces project. A sample of the potential screened actinobacteria was prepared according to the protocol described by Srinivasan et al. 2014 [22] and external morphology of the isolate studied using scanning electron microscopy (SEM). The micromorphology of the spore bearing hyphae with entire spore chain along with the substrate and aerial mycelium was examined under SEM. The cultural traits of the strain were recorded on different media which included tryptoneyeast extract agar (ISP-1), YMD agar (ISP-2), oatmeal agar (ISP-3), starch inorganic salts agar (ISP-4), glycerol asparagine agar (ISP-5), peptone yeast extract iron agar (ISP-6), tyrosine agar (ISP-7), starch-casein agar, Czapek-Dox agar, and nutrient agar media [23].

The utilization of carbohydrates by the strain was carried out in minimal medium containing different carbon sources at $1 \%$ concentration according to the method described by Isik et al. [24].

Physiological characterization such as the effect of $\mathrm{pH}$, temperature, and salinity was analyzed. $\mathrm{NaCl}$ tolerance of the strain was determined through the technique suggested by Ellaiah et al. [25]. Biochemical tests, namely, catalase and coagulase were also evaluated.

Molecular characterization by 165 rRNA sequencing of the potential streptomyces strain producing antifungal compounds The genomic DNA used for the polymerase chain reaction analysis was prepared from the single colonies grown on the yeast extract malt extract dextrose agar (ISP-2) medium for 7 days. Genomic DNA extracted from the potent strain (BS-26) was isolated employing the DNA purification Kit (Pure Fast Bacterial Genomic DNA purification kit, Helini Biomolecules, India) consistent with the manufacturer protocol. The 16S rRNA gene fragment was amplified using universal primers (forward primer-5- AGAGTTTGATCCTGGCTCAG -3 and reverse primer-5- AAGGAGGTGATCCAGCCGCA -5). The whole Genomic DNA extraction was done [26] and the 16S rRNA sequence of the isolate was subjected to BLAST similarity search tool. The phylogeny (using NCBI) analysis of query sequence with the closely related BLAST result was performed followed by multiple sequence alignment using the program subject sequences of MUSCLE 3.7 [27]. The phylogenetic analysis was performed using the MEGA software package (ver. 6.0) to construct phylogenetic tree based on the neighbor-joining method. The $16 \mathrm{~S}$ rRNA gene (rRNA) sequence of the strain BS-26 was registered in the GenBank submission.

\section{Extraction of crude secondary metabolites}

The clear culture filtrate $(1 \mathrm{~L})$ was extracted twice with ethyl acetate (EA) of $1: 1(\mathrm{v} / \mathrm{v})$ and shaken vigorously for $1 \mathrm{~h}$ for complete extraction. The EA phase that contains bioactive compound was separated from the aqueous phase. The extracts were pooled and concentrated by rotary evaporation at $40^{\circ} \mathrm{C}$. The solvent was evaporated leaving behind the organic residue. The obtained organic residue was subjected to thin-layer chromatography (TLC) separation.

\section{TLC separation}

The presence of compounds was analyzed by TLC using TLC aluminum sheets with chloroform and methanol at 9.5: 0.5 ratio $(\mathrm{v} / \mathrm{v})$ as solvent system.

The spots were viewed under ultraviolet light for visualization of the spot whose Rf value was calculated using the following formula:

$$
\mathrm{Rf}=\frac{\text { Distance traveled by the compound }}{\text { Distance traveled by the solvent }}
$$

\section{Bioautography}

Bioautography methods use in this study was employed as a suitable method for direct detecting of antifungal fraction from the crude extract. Antifungal metabolites can be already located on the plates by observing clear zones where active compounds inhibit fungal growth.

Inhibition of fungal growth on chromatographic plate was checked by TLC bioautography system. The chromatogram was kept for evaporation of the solvent. Developed chromatogram was placed on sterile PDA plate. PDA with antagonistic fungal spore suspension was poured on chromatogram. Zone of inhibition was checked after 7 days of incubation.

Antifungal secondary metabolites were located on the plates by observing clear zones where active compound inhibit the fungal growth. Zone of inhibition was checked after incubation [28] period.

\section{RESULTS}

\section{Screening of potential actinobacterial strain} Primary screening

Among the 20 actinobacterial isolates that were subjected to antagonistic test by primary screening method, six isolates showed potential inhibition against $M$. oryzae fungal pathogen.

\section{Secondary screening}

The six primarily screened actinobacterial isolates were subjected to secondary screening using agar well diffusion method. There was no inhibition zone detected in negative control plate around wells loaded with diluted sterile broth. The inhibition zone in positive control plate with crude bioactive compound of actinobacterial culture was observed to be $22 \mathrm{~mm}$. The zone of inhibition got by the isolate BS-26 was significantly high followed by the isolate BS-18 when compared to all others. From the results of secondary screening, it was observed that BS-26 isolate produced the largest inhibiting zone of diameter $22 \mathrm{~mm}$ and BS-18 isolate produced the next largest inhibiting zone of diameter $18 \mathrm{~mm}$ (Fig. 1) at $144 \mathrm{~h}$ of incubation (from $6^{\text {th }}$ day of inoculation) which stabilized thereon. All the other tested isolates produced zones ranging from 5 to $10 \mathrm{~mm}$ diameter during the assays. 
Morphological, cultural, physiological, and biochemical characteristics of strain BS-26

Morphological characterization (Fig. 2)

\begin{tabular}{ll}
\hline Morphological characters & Response \\
\hline Colony & Mycelial \\
Spore chain morphology & Retinaculiaperti \\
Spore surface & Smooth \\
Color of aerial mycelium (ISP-2) & Greyish white \\
Color of substrate mycelium (ISP-2) & Pale yellow \\
\hline
\end{tabular}

\section{Cultural characteristics}

Cultural characteristics of the strain on various ISP and non-ISP media

BS-26 growth was good in ISP-1, ISP-2, ISP-3, ISP-4, and starch-casein agar; moderate in ISP-5, ISP-6, ISP-7, and nutrient agar; and poor in Czapek-Dox agar (Table 1).

\section{Utilization of the carbon sources}

Carbon source such as glucose, sucrose, fructose, arabinose, mannose, xylose, rhamnose, and inositol is utilized except raffinose.

\section{Physiological characters}

\begin{tabular}{ll}
\hline Grams reaction & + \\
\hline Acid-fast reaction & - \\
Production of melanin pigment & - \\
Range of temperature for growth & $25-40^{\circ} \mathrm{C}$ \\
Optimum temperature for growth & $30 \mathrm{C}$ \\
Range of pH for growth & $6-9$ \\
Optimum pH for growth & 7.5 \\
NaCl tolerance & $9 \%$ \\
\hline
\end{tabular}

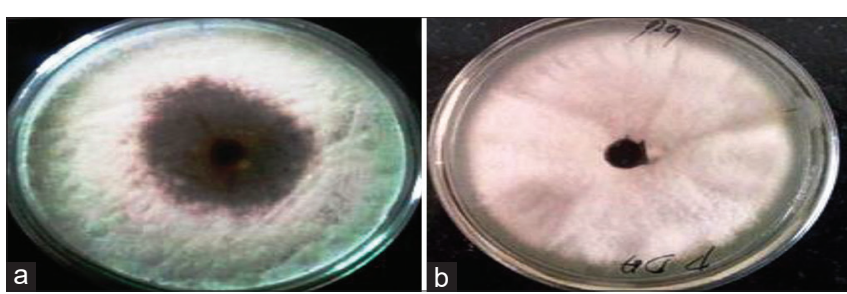

Fig. 1: The inhibition zone of BS-26 compared to the control plate (a) P. oryzae controlled by BS-26 (b) control plate

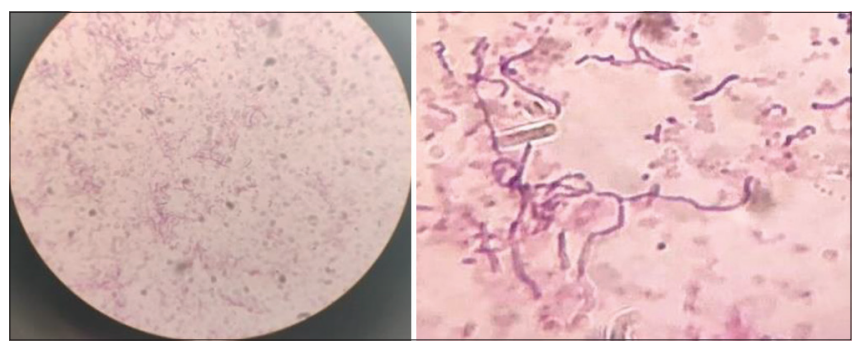

Fig. 2: Micromorphological observation by light microscope
Biochemical characters

\begin{tabular}{lc}
\hline Catalase & + \\
\hline Starch hydrolysis & - \\
Oxidase & - \\
Casein hydrolysis & - \\
Bile esculin & + \\
\hline
\end{tabular}

The morphological characteristics, cultural characteristics, physiological characteristics, and pattern of utilization of carbon sources of the strain BS-26 revealed that the strain belong to the genus Streptomyces [29].

\section{Molecular characterization}

A phylogenetic tree based on neighbor-joining method for strain BS26 along with its closest relatives of the genus Streptomyces was given (Fig. 3). The $16 \mathrm{~S}$ rRNA gene sequence of strain BS-26 has 100\% similarity with Streptomyces violaceoruber. The sequence had been submitted to the GenBank under the accession number Streptomyces MH559817.

\section{Extraction of crude secondary metabolites}

The secondary metabolites were extracted from the cell-free culture supernatant using EA. EA extract showed the highest inhibition than other solvent extracts. The obtained organic residue was subjected to TLC separation.

\section{TLC separation}

The presence of compounds was analyzed by TLC using TLC silica aluminum sheet with chloroform and methanol at 9.5: 0.5 ratio $(\mathrm{v} / \mathrm{v})$ as solvent system (Fig. 4).

Determination of Rf value of the compound.

$$
\begin{gathered}
\mathrm{Rf}=\frac{\text { Distance traveled by the compound }}{\text { Distance traveled by the solvent }} \\
\text { The result of Rf value }: \frac{3.5}{5.1}=0.68
\end{gathered}
$$

\section{Bioautography}

Clear zones of inhibition against M. Oryzae showed that the culture of S. violaceoruber produced secondary metabolites (Fig. 5).

\section{DISCUSSION}

The rice blast infection is a major biotic stress caused for the rice crops which is considered as one of the most damaging diseases worldwide and distributed in about 85 countries throughout all continents where the rice crop is cultivated. In India alone, the total loss due to rice blast was 265,000 ton total rice production annually. However, blast under severe epiphytic conditions may result between 70 and $90 \%$ losses in isolated fields [30]. Other susceptible factors, that is, high mean temperature values, degree of relative humidity higher than $85-89 \%$, presence of dew, drought stress, and excessive nitrogen fertilization favor epidemic development [31]. Ashkani et al. [32] reported that it can cause yield loss between 30 and 50\% in large rice producing areas even under favorable environmental conditions. Although fungicides can be used to control rice blast, they generate additional costs in rice

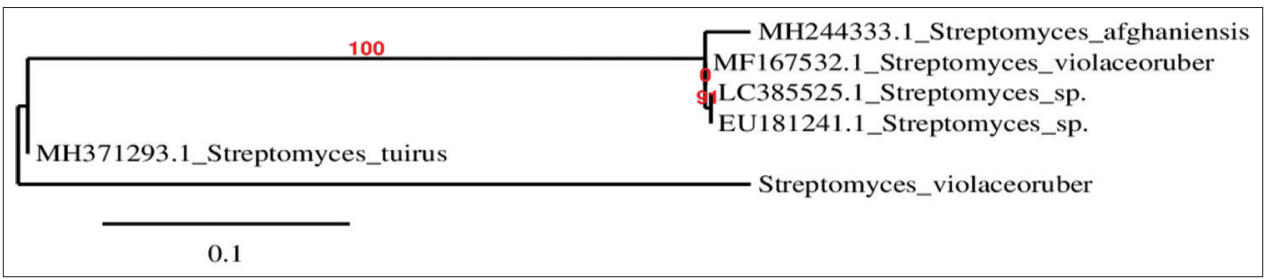

Fig. 3: Highly similar sequence to BS-26 
Table 1: Cultural characteristics of the strain on various ISP and non-ISP media

\begin{tabular}{|c|c|c|c|c|c|}
\hline S. No & Medium & Growth & Aerial mycelium & Substrate mycelium & Pigmentation \\
\hline 1 & Tryptone-yeast extract agar (ISP-1) & Good & White & Pale yellow & Nil \\
\hline 2 & Yeast extract malt extract dextrose agar (ISP-2) & Good & Greyish-white & Yellow & Nil \\
\hline 3 & Oatmeal agar (ISP-3) & Good & White & Pale yellow & Nil \\
\hline 4 & Inorganic salts starch agar (ISP-4) & Good & White & Pale yellow & Nil \\
\hline 5 & Glycerol asparagine agar (ISP-5) & Moderate & White & Pale yellow & Nil \\
\hline 6 & Peptone yeast extract iron agar (ISP-6) & Moderate & White & White & Nil \\
\hline 7 & Tyrosine agar (ISP-7) & Moderate & White & Yellow & Nil \\
\hline 9 & Nutrient agar & Moderate & Greyish-white & Pale yellow & Nil \\
\hline 10 & Czapek-Dox agar & Poor & - & - & - \\
\hline
\end{tabular}

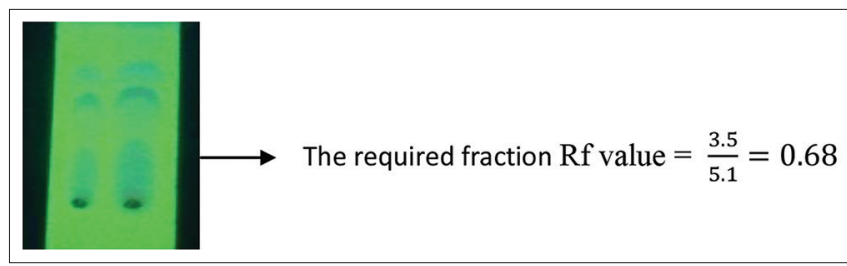

Fig. 4: Thin-layer chromatography separation

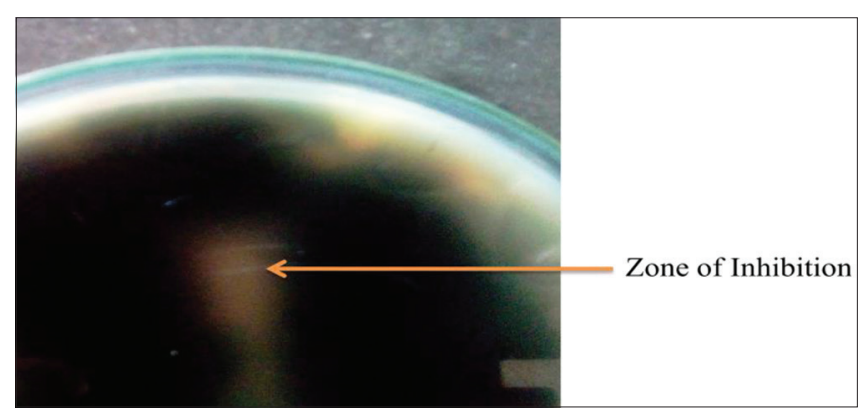

Fig. 5: Bioautography

production and chemical contamination of environment and foods. Therefore, the use of biocontrol solution is needed for rice blast disease management to make significant progress in rice cultivation. Reducing the use of chemical fungicides, pesticides with biocontrol replacement are better solutions to maintain the crop productivity without damaging the ecosystem. Many studies have been conducted on actinobacteria, highlighting the ability of these micro-organisms to promote plant growth and their synergistic effects on plant growth and protection [33]. In the present study, the antifungal activity of secondary metabolites from $S$. violaceoruber was evaluated against $M$. oryzae. The extent of zone formation reflected the inhibition ability of actinobacteria upon the spore germination and mycelia formation of fungal pathogen M. oryzae. Bioautography technique was very useful for detection of antifungal compound from the extract on thin-layer chromatograms.

In a previous study [34], it was reported that $S$. violaceoruber had invariably acted as an antagonist to both native and inoculated plant pathogen and helped in plant growth. The antifungal metabolites of present study $S$. violaceoruber can be exploited to indirectly plant growth by inhibiting disease causing pathogens.

\section{CONCLUSION}

$S$. violaceoruber has the ability to produce antifungal compound. Therefore, this isolate proves to be a promising microbe which can be further studied for its applications a biocontrol agent against rice blast fungi. In this study, the antifungal activity of secondary metabolites of $S$. violaceoruber was evaluated against $M$. oryzae and the results suggest that their natural compound could be a potential alternative for controlling rice blast disease.

\section{ACKNOWLEDGMENT}

The authors thank the Department of Microbiology, Periyar University for providing all the lab facilities for this study.

\section{AUTHORS' CONTRIBUTIONS}

Experimentations and data analysis - R. Thilagam, result interpretation - Dr. N. Hemalatha, actinobacterial strains supply-Dr. R. Balagurunathan and M. Sangeetha.

\section{CONFLICTS OF INTEREST}

There are no conflicts of interest.

\section{AUTHORS' FUNDING}

No fund.

\section{REFERENCES}

1. Smith RM, Peterson WH, McCoy E. Oligomycin, a new antifungal antibiotic. Antibiot Chemother 1954;4:962-70.

2. Kim BS, Moon SS, Hwang BK. Isolation, identification, and antifungal activity of a macrolide antibiotic, oligomycin A, produced by Streptomyces libani. Can J Bot 1999;77:850-8.

3. Yang PW, Li MG, Zhao JY, Zhu MZ, Shang H, Li JR, et al. Oligomycins $\mathrm{A}$ and $\mathrm{C}$, major secondary metabolites isolated from the newly isolated strain Streptomyces diastaticus. Folia Microbiol 2010;55:10-6.

4. Robertson J, Stevens K. Pyrrolizidine alkaloids. Nat Prod Rep 2014;31:1721-88.

5. Awla HK, Kadir J, Othman R, Rashid TS, Wong MY. Bioactive compounds produced by Streptomyces $s p$. isolate UPMRS4 and antifungal activity against Pyricularia oryzae. Am J Plant Sci 2016;7:1077-85.

6. Zhou L, Zhang X, Li C, Christensen MJ, Nan Z. Antifungal activity and phytochemical investigation of the asexual endophyte of Epichloë sp. from Festuca sinensis. Sci China Life Sci 2015;58:821.

7. Mishra J, Tewari S, Singh S, Arora NK. Biopesticides: Where we stand. In: Plant Microbes Symbiosis: Applied Facets. Vol. 37. 2015. p. 75.

8. Tyc O, Song C, Dickschat JS, Vos M, Garbeva P. The ecological role of volatile and soluble secondary metabolites produced by soil bacteria. Trends Microbiol 2017;25:280-92.

9. Adegboye MF, Babalola OO. Taxonomy and ecology of antibiotic producing actinomycetes. Afr J Agric Res 2012;7:2255-61.

10. Jog R, Nareshkumar G, Rajkumar S. Enhancing soil health and plant growth promotion by actinomycetes. In: Plant Growth Promoting Actinobacteria. Berlin, Germany: Springer 2016. p. 33-45.

11. El Tarabily KA, Nassar AH, Sivasithamparam K. Promotion of growth of bean (Phaseolus vulgaris L.) in a calcareous soil by a phosphate solubilizing, rhizosphere-competent isolate of Micromonospora endolithica. Appl Soil Ecol 2008;39:161-71.

12. El-Tarabily KA, Sivasithamparam K. Non-streptomycete actinomycetes as biocontrol agents of soil-borne fungal plant pathogens and as plant growth promoters. Soil Biol Biochem 2006;38:1505-20.

13. Compant S, Duffy B, Nowak J, Clément C, Barka EA. Use of plant growth-promoting bacteria for biocontrol of plant diseases: Principles, mechanisms of action, and future prospects. Appl Environ Microbiol 2005;71:4951-9.

14. Mavrodi DV, Peever TL, Mavrodi OV, Parejko JA, Raaijmakers JM, 
Lemanceau $\mathrm{P}$, et al. Diversity and evolution of the phenazine biosynthesis pathway. Appl Environ Microbiol 2010;76:866-79.

15. Chin-A-Woeng TF, Thomas-Oate JE, Lugtenberg BJ, Bloemberg GV. Introduction of the phzH gene of Pseudomonas chlororaphis PCL1391 extends the range of biocontrol ability of phenazine-1-carboxylic acid-producing Pseudomonas spp. strains. Mol Plant Microb Interact 2001;14:1006-15.

16. Bharti A, Kumar V, Gusain O, Bisht GS. Antifungal activity of actinomycetes isolated from Garhwal region. J Sci Eng Tech Mgt 2010;2:3-5.

17. Soares AC, Sousa CD, Garrido MD, Perez JO, Almeida NS. Soil streptomycetes with in vitro activity against the yam pathogens Curvularia eragrostides and Colletotrichum gloeosporioides. Braz J Microbiol 2006;37:456-61.

18. Jain PK, Jain PC. Isolation, characterization and antifungal activity of Streptomyces sampsonii GS 1322. Indian J Exp Biol 2007;45:203-6.

19. Chaudhary HS, Yadav J, Shrivastava AR, Singh S, Singh AK, Gopalan N. Antibacterial activity of actinomycetes isolated from different soil samples of Sheopur (A city of central India). J Adv Pharm Technol Res 2013;4:118.

20. Riungu GM, Muthomi JW, Narla RD, Wagacha JM, Gathumbi JK. Management of Fusarium head blight of wheat and deoxynivalenol accumulation using antagonistic microorganisms. Plant Pathol 2008; 7:13-9

21. Bhavya T, Padma S. Antifungal activity of Cymbopogon citratus leaves extract against herbal drug contaminants. World J Pharm Pharm Sci 2014;3:768-75.

22. Srinivasan V, Mukkayyan N, Ajitkumar P. Highly deviated asymmetric division in very low proportion of mycobacterial mid-log phase cells. Open Microbiol J 2014;8:40

23. Shirling ET, Gottlieb D. Methods for characterization of Streptomyces species. Int J Syst Evol Microbiol 1966;16:313-40.

24. Isik K, Chun J, Hah YC, Goodfellow M. Nocardia salmonicida nom. rev., a fish pathogen. Int J Syst Evol Microbiol 1999;49:833-37.

25. Ellaiah P, Adinarayana G, Saisha V, Vasu P. An oligoglycosidic antibiotic from a newly isolated Streptomyces albovinaceus. Indian J Microbiol 2005;45:33.

26. Sambrook HC. Molecular Cloning: A Laboratory Manual. Philadelphia, PA: Williams and Wilkins Co., 1961.

27. Edgar RC. MUSCLE: Multiple sequence alignment with high accuracy and high throughput. Nucleic Acids Res 2004;32:1792-7.

28. Suleiman MM, McGaw LI, Naidoo V, Eloff J. Detection of antimicrobial compounds by bioautography of different extracts of leaves of selected South African tree species. Afr J Tradit Complement Altern Med 2010;7:64-78.

29. Waksman SA. The Actinomycetes. Vol. II. Classification, Identification and Descriptions of Genera and Species. London: Baillière, Tindall \& Cox, Ltd., 7 \& 8, Henrietta Street, W.C.2.1961. pp.ix+363pp.

30. Devanna NB, Vijayan J, Sharma TR. The blast resistance gene Pi54 of cloned from Oryza officinalis interacts with Avr-Pi54 through its novel non-LRR domains. PLoS One 2014;9:e104840.

31. Piotti E, Rigano MM, Rodino D, Rodolfi M, Castiglione S, Picco AM, et al. Genetic structure of Pyricularia grisea (Cooke) Sacc. isolates from Italian paddy fields. J Phytopathol 2005;153:80-6.

32. Ashkani S, Rafii MY, Shabanimofrad M, Miah G, Sahebi M, Azizi P, et al. Molecular breeding strategy and challenges towards improvement of blast disease resistance in rice crop. Front Plant Sci 2015;6:886

33. Merzaeva OV, Shirokikh IG. Colonization of plant rhizosphere by actinomycetes of different genera. Microbiology 2006;75:226-30.

34. Thilagam R, Hemalatha N. Plant growth promotion and chilli anthracnose disease suppression ability of rhizosphere soil Actinobacteria. J Appl Microbiol 2019;126:1835-49. 